\title{
Design optimization study of a torus type axial flux machine
}

\author{
Serdal Arslan \\ Harran University, Birecik Vocational School, Şanlıurfa, Turkey, serdalarslan@harran.edu.tr, \\ https://orcid.org/0000-0002-1187-5633 \\ Erol Kurt
}

Gazi University, Technology Faculty, Department of Electrical and Electronics Engineering, Ankara, Turkey, ekurt52tr@gmail.com, orcid.org/0000-0002-3615-6926

\section{Ortzi Akizu}

Basque Country University (UPV/EHU), Faculty of Engineering, Department of Graphic Expression and Engineering Projects, Vitoria-Gasteiz, Spain, ortzi.akizu@ehu.eus, orcid.org/0000-0001-9018-1922

\section{Jose Manuel Lopez-Guede}

Basque Country University (UPV/EHU), Faculty of Engineering, Department of Engineering Systems and Automatics, Vitoria-Gasteiz, Spain, jm.lopez@ehu.es, orcid.org/0000-0002-5310-1601

Abstract: Axial flux machines are used frequently in wind energy applications due to their high power densities and efficiencies. However, the parametrical dependencies of those generators affect the generated power and efficiencies. For instance, turbine blade structures dimensions, change dramatically the speed and torque characteristics. Hence, this study includes a pursuit of optimization and the related design parameters for an axial generator in terms of its off grid operations. The analytical design relations and simulated data have shown that the geometric dimensions and morphology of the machine can be analyzed effectively under the finite element method and the optimization of the machine can be provided with a good accuracy by applying the response surface optimization. Cogging torque and power density formulated aim function gives a good optimization for the design. According to this approach, the general performance of the machine is maximized and the cogging torque and weight are kept to be decreased. Design variables are optimized by considering the generator size. Consequently, an optimal $4.8 \%$ increase in weight can yield to a $27.4 \%$ power enhancement in the machine.

Keywords: $\quad$ Torus design, Response surface, Axial machine, Wind energy

Arslan, S., Kurt, E., Akizu, O., Lopez-Guede, J.M., Design optimization study of a

Cite this paper as: $\quad$ torus type axial flux machine. Journal of Energy Systems 2018; 2(2): 43-56, DOI: 10.30521/jes. 408179 


\section{INTRODUCTION}

The explorations on the axial flux machines (AFMs) have an increasing trend due to the invention of new core and permanent magnet materials, consideration of efficient flux morphologies, identifications of various rotor -stator- slot combinations and geometries of teethes and permanent magnets (PMs) and the introduction of cogging torque reduction techniques [1,2]. Besides, the applications of AFMs increase from time to time in wind energy, electrical vehicles, chargers, tidal energy, etc [3-6].

AFMs have differences compared to the radial flux machines (RFMs) in terms of flux direction and stator structures. Therefore, sizing formulations have considerably change from RFMs. Indeed, many previous studies have proven that the electromagnetic air gap shear stress depends on the multiplication of machine diameter and length in RFMs, whereas the same ratio depends on only the cubic power of diameter in AFMs. Consequently, slight changes in the diameter should affect the output power substantially. AFM also differs in geometries, design factors and methodologies compared to the RFMs. On the other hand, the PM arrays in RFMs can be adapted to any AFM by using Halbach [7], embedded or surface mounted type locations. When symmetric geometries are considered, analytical methods can assist to solve the designs, however complicated 3D machines can only be solved by a well-defined finite element analysis (FEA).

According to literature [8,9], machine designers realize the optimization studies by considering the total or local parameters, such us, weight, cost, power density, cogging torque. In order to compensate their goal, have been applied a number of optimization techniques such as genetic algorithms, pattern search, sequential nonlinear programming, response surface, etc. [10-12]. Among them, the response surface method has been performed in many designs such as PM synchronous motor, brushless dc motor, double fed induction motor, linear machine, reluctance motor, actuators, transformers [12-33]. For instance, Kahourzade et al [8] have studied the optimization of a $1 \mathrm{~kW}$, three phase, 4 pole axial machine via a genetic algorithm. They used back-EMF and power density as main optimization parameters. In other study, Yang et al [34] have practiced a differential evolution algorithm for the optimization by considering efficiency and torque density as main parameters for a single side axial machine. A further optimization study has been performed by Hwang et al. [35] for a $400 \mathrm{~W}$ machine. Their goal has been to decrease the torque ripple and increase the averaged mechanical torque. For that goal, they have used the so-called Taguchi method. Mahmoudi et al. performed another optimization for a $1 \mathrm{~kW}$ torus type AFM by using analytical and numeric approaches [36]. They mainly used the genetic algorithm technique and FEA for the power density increase and cogging torque decrease in their machine. BackEMF and cogging torque tests were also handled by them.

Going further than current literature, this work has the novel aim to make an optimization study for a torus type machine by considering the parameters weight and power density via the FEA. In this manuscript, while Section 2 shows the analysis of sizing equations and geometry of the machine, Section 3 briefly describes the response surface method and FEA. The next section gives the main findings from optimization analysis and the concluding remarks have been presented in the last section.

\section{ANALYTICAL SIZING EQUATION}

In order to size the electric machines, power formulations are vital, thereby it can be stated that the machine size should be proportional to then output power at a constant frequency. If $\mathrm{T}, \eta, m, e(t)$, 
$i(t)$ are period, estimated efficiency, phase number, phase voltage and phase current, respectively, Eq. 1 gives the output power of the machine as in previous studies [35-37]:

$$
\begin{gathered}
P_{\text {out }}=\eta \frac{m}{\mathrm{~T}} \int_{0}^{\mathrm{T}} e(t) \cdot i(t) d t=m K_{p} \eta E_{p k} I_{p k} \\
K_{i}=\frac{I_{p k}}{I_{r m s}} \text { and } K_{e}=\frac{E_{p k}}{E_{r m s}}
\end{gathered}
$$

In this equations $K_{i}$ and $K_{e}$ refer to current and voltage wave factors, respectively. The maximal induced voltage and current can be stated by Eqs. 3 and 4. According to some previous works, the ratio of the diameters of outer and inner parts are considered around $\lambda=1 / \sqrt{3}$ [35-37]. Therefore, the extracted ratio has been used for the overall study.

$$
\begin{aligned}
E_{p k} & =K_{e} N_{f} B_{g} \frac{f}{p}\left(1-\lambda^{2}\right) D_{0}^{2} \\
I_{p k} & =A \pi K_{i} \frac{1+\lambda}{2} \frac{D_{0}}{2 m_{1} N_{f}}
\end{aligned}
$$

Above, $N_{f}, B_{g}, \mathrm{f}, \mathrm{p}, \lambda\left(D_{i} / D_{o}\right)$ and A are winding turn per phase, air gap flux density, frequency, pole number, the ratio of diameters and electrical loading. After substituting Eqs. 3 and 4 to Eq. 1, one arrives at,

$$
P_{\text {out }}=\frac{1}{1+K_{\phi}} \frac{m}{m_{1}} \frac{\pi}{2} K_{e} K_{i} K_{p} K_{L} \eta B_{g} A \frac{f}{p}\left(1-\lambda^{2}\right)\left(\frac{1+\lambda}{2}\right) D_{0}^{2} L_{e}
$$

Here $L_{e}, K_{\phi}, K_{L}$ are axial length of the machine, electrical loading ratio on the rotor and stator and the aspect ratio coefficient [38]. These parameters are also in interest due to the fact that they affect the loss, temperature rise, and design efficiency requirements of the structure.

Our analyses are based on a 36-slot 12- pole dual-rotor single-stator AFPM machine as presented in Fig. 1 and 3. This type machine is called slotted as "torus" with back-to-back gramme-ring type winding. The stator and rotor comprise a tape wound core and a mild-steel disc and fan-shaped surface-mounted magnets, respectively. Then, the generalized sizing equation approach can be computed as follows:

$$
D_{0}=\sqrt[3]{\frac{\pi m}{\frac{\pi m}{2 m_{1}} K_{e} K_{p} K_{i} A B_{g} \eta \frac{f}{p}\left(1-\lambda^{2}\right)\left(\frac{1+\lambda}{2}\right)}}
$$

Here, g, Lr and Ls are airgap, rotor length and stator length. Then open arrives at the total length as:

$$
L_{e}=L_{s}+2 L_{r}+2 g
$$

Note that the stator and rotor lengths are given by:

$$
L_{s}=L_{s c}+2 L_{s t} \text { and } L_{r}=L_{r c}+L_{m}
$$

While considering the flux densities for stator and rotor (i.e. $B_{s c}$ and $B_{r c}$ ), the lengths can be defined as 


$$
\begin{gathered}
L_{s c}=\frac{B_{g} \pi \alpha_{p} D_{o}(1+\lambda)}{4 p B_{s c}} \\
L_{r c}=\frac{B_{g} \pi D_{o}(1+\lambda)}{8 p B_{r c}} \\
L_{m}=\frac{\mu_{r} B_{g}}{B_{r}-\left(\frac{B_{g p k}}{K_{d}}\right)} K_{c} g
\end{gathered}
$$

Where $\mu_{r}$ is the relative recoil magnetic permeability of the PM, $B_{r}$ is the PM residual flux density, $K_{d}$ is the leakage flux factor, and $K_{c}$ is the Carter factor. Then, one arrives to output power as:

$$
P_{\text {out }}=V_{a} I_{a}+V_{b} I_{b}+V_{c} I_{c}
$$

V and I are induced voltage and phase current, respectively. In addition, a, b, and c denote phases.
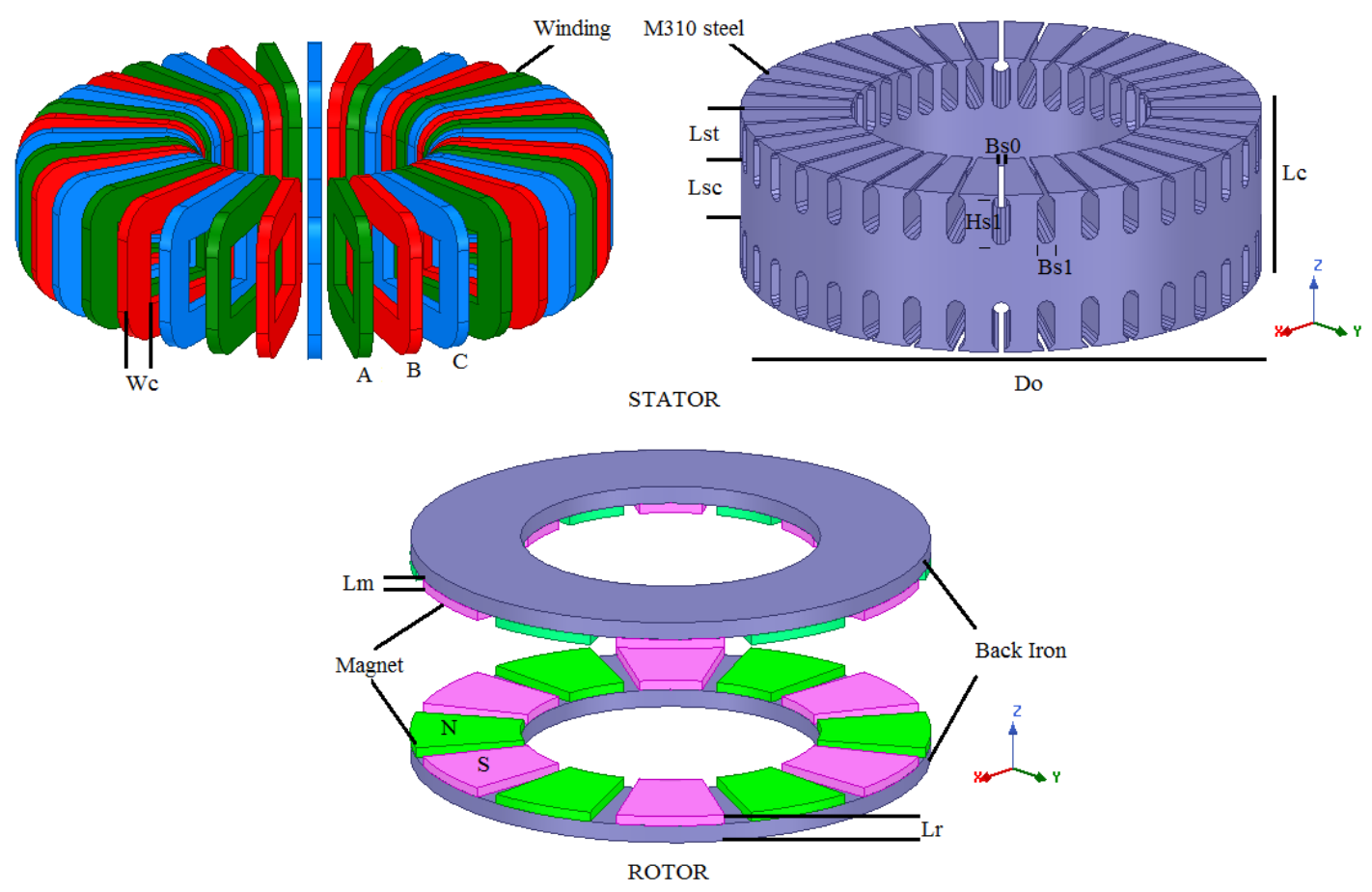

Figure 1. A torus types axial flux machine components

Table 1 presents the sizing information for the machine. The core loss combines eddy current losses and hysteresis losses for a transient solution type as usual. It is a post-processing calculation, based on already calculated transient magnetic field quantities. On the other hand, the core loss is expressed by,

$$
P_{c o}=P_{h}+P_{c}+P_{e}
$$

In addition, hysteresis loss is

$$
P_{h}=k_{h} \cdot B_{m}^{2} \cdot f
$$


Table 1. Preliminary sizing values and features

\begin{tabular}{llrcclr}
\hline Parameter & Definition & Value & Unit & Parameter & Definition & Value \\
\hline$P_{\text {out }}$ & Output Power & 1500 & $\mathrm{VA}$ & $2 \mathrm{p}$ & Pole Number & 12 \\
$\mathrm{n}$ & Revolutions & 500 & $\mathrm{rpm}$ & $\eta$ & Efficiency & 0.92 \\
$\mathrm{f}$ & Frequency & 50 & $\mathrm{~Hz}$ & $\mathrm{Xs}$ & Slot Number & 36 \\
$\mathrm{Do}$ & Outer Diameter & 0.2334 & $\mathrm{~m}$ & $\lambda$ & Inner to outer diameter ratio & 0.5773 \\
$\mathrm{~A}$ & Electrical Loading & 19500 & $\mathrm{~A} / \mathrm{m}$ & $\mathrm{m}$ & Phase Number & 3 \\
$\mathrm{Bg}$ & Flux Density in airgap & 0.5 & $\mathrm{~T}$ & $\alpha_{p}$ & Pole pitch ratio & 0.8 \\
Bs1 & Slot opening & 8 & $\mathrm{~mm}$ & $N_{f}$ & Number of turns per phase & 192 \\
$\mathrm{Hs} 2$ & Slot height & 15 & $\mathrm{~mm}$ & $k_{w}$ & Fundamental winding factor & 1 \\
Bs0 & The upper opening of slot & 2.5 & $\mathrm{~mm}$ & $k_{c o g}$ & Least common multiple & 36 \\
Lm & Magnet Thickness & 0.0045 & $\mathrm{~mm}$ & & & \\
$J$ & Current Density & 3.25 & $\mathrm{~A} / \mathrm{mm} 2$ & & & \\
$R_{f}$ & Phase Resistance & 10.75 & $\mathrm{ohm}$ & & & \\
\hline
\end{tabular}

Where the eddy-current loss and the excess core loss are,

$$
P_{c}=k_{c} \cdot B_{m}^{2} \cdot f^{2} \text { and } P_{e}=k_{e} \cdot B_{m}^{1.5} \cdot f^{1.5}
$$

The copper loss is stated as,

$$
P_{c u}=3 R_{f} I_{r m s}^{2}
$$

Here, $R_{f}$ and $I_{r m s}$ are the resistance of single phase and the effective value of phase current, respectively. The efficiency is defined by,

$$
\eta=\frac{P_{\text {out }}}{P_{\text {out }}+P_{c u}+P_{c o}}
$$

The machine power density (i.e. $P_{d}$ ) for total volume is given by,

$$
P_{d}=\frac{P_{\text {out }}}{\frac{\pi}{4}\left(D_{o}+2 W_{c}\right)^{2} L_{e}}
$$

\section{RESPONSE SURFACE AND FINITE ELEMENT METHODS}

Response Surface Methodology (RSM) is a partially empirical and numerical method, which deals with the exploration of the relations among various physical parameters of any system by a statistical approach [39]. Therefore, the usage of experimental findings and their statistical interpretation become an important goal for the application of the RSM. A comprehensive flow diagram of RSM is sketched in Fig. 2. 
The selection of the variables can be realized based on a mathematical model or a correlation analysis. Besides, if the subject has already been explored in the literature with a well-defined variable set, those can also be used. For instance, in terms of cogging torque, the variables such as pole pitch ratio, slot number, etc. can be counted among those with that regard. The model equations used in the analyses can be in first or second orders. Meanwhile, frequently the second order equations have been used in such electrical engineering problems. In that sense, a general statement with all variables and the error part can be simplified as follows:

$$
y=f\left(x_{1}, x_{2}, x_{3}, x_{4}, x_{5}, \ldots, x_{n}\right)+\varepsilon
$$

Note that $y$ denotes the response, while $x_{n}$ and $\varepsilon$ define the independent variables and errors. Here $y$ can be efficiency, output power, cogging torque, etc. The design variables are $L m, A l f a\left(\alpha_{p}\right), A$ and the measured value $y$ and the estimated value $y$ difference can be assigned as error as,

$$
y=f(x)+\varepsilon
$$

RSM can be determined as the interaction of the variables in a second order function by,

$$
y=\beta_{0}+\sum_{i=1}^{n} \beta_{i} X_{i}+\sum_{i=1}^{n} \beta_{i i} X_{i}^{2}+\sum_{i=1}^{n} \sum_{j=1}^{n} \beta_{i j} X_{i} X_{j}+\varepsilon_{0}
$$

Here $\beta_{0}$ is a model constant, $\beta_{i}, \beta_{i i}$ and $\beta_{i j}$ are variable coefficients and $x_{i}$ and $x_{j}$ are the coded independent variables. After the determination of a second order function for variables, the optimal responses of the variables such as $x_{1}, x_{2}, \ldots, x_{n}$ can be defined in which manner governing the relation. That point, which optimizes the response variable (if any) should be found following the zeroequality of the differentiation with respect to the variables $x_{1}, x_{2}, \ldots, x_{n}$. In fact, the designs for seeking the optimization point can frequently be the central united or Box-Behnken experimental designs. Those designs can state the relation among the variables rather than a linear correlation. In reality, the gradient to reach the minimal or maximal value would be the main task and the experiments can be decreased more to observe the effects of the independent variables [40]. The important point is that the most effective independent variable, which affects the dependent variables most, should be determined during the process.

Our electromagnetic analysis has been performed in Ansys RMxprt. Initially, the electromagnetic design has been realized and assigned to the RMxprt. The overall 3D-FEA model of the machine is shown in Fig. 3(a). While selecting transient analysis mode, the master-slave configuration should be determined in order to use the simulation time appropriately (see in Fig. 3(b)). 30 degrees' partial region is sufficient for that aim. In that model, boundary conditions, winding turns, resistance/inductance parameters are given. Then, an appropriate meshing should be performed. For correct meshing purpose, especially the magnetic and conducting materials require more importance and sharp ends, or circling regions would need more mesh elements than the regular regions. Airgaps, cores and winding regions are important regions in that sense. By using winding currents as sources, each component is activated in the machine and both magnetic field strength $(\mathrm{H})$ and current density $(\mathrm{J})$ are calculated for each trapezoidal mesh element by considering the values at its corners and mid-edges. Note that the $\mathrm{B}-\mathrm{H}$ curve of the core is vital, too. Following the validation, phase currents and voltages, electromagnetic torque, flux and losses are measured. Besides, efficiency (Eq. 17) and power density (Eq. 18) can be determined. The Central Composite Design (CCD) provides a screening set in order to determine the overall trends of the metamodel to a better guide options in Optimal Space-Filling Design. In that manner, the Genetic Aggregation Response Surface finds the best possible response surface for each output. A fitness factor can operate to minimize error including the cross-validation errors for the outputs. 


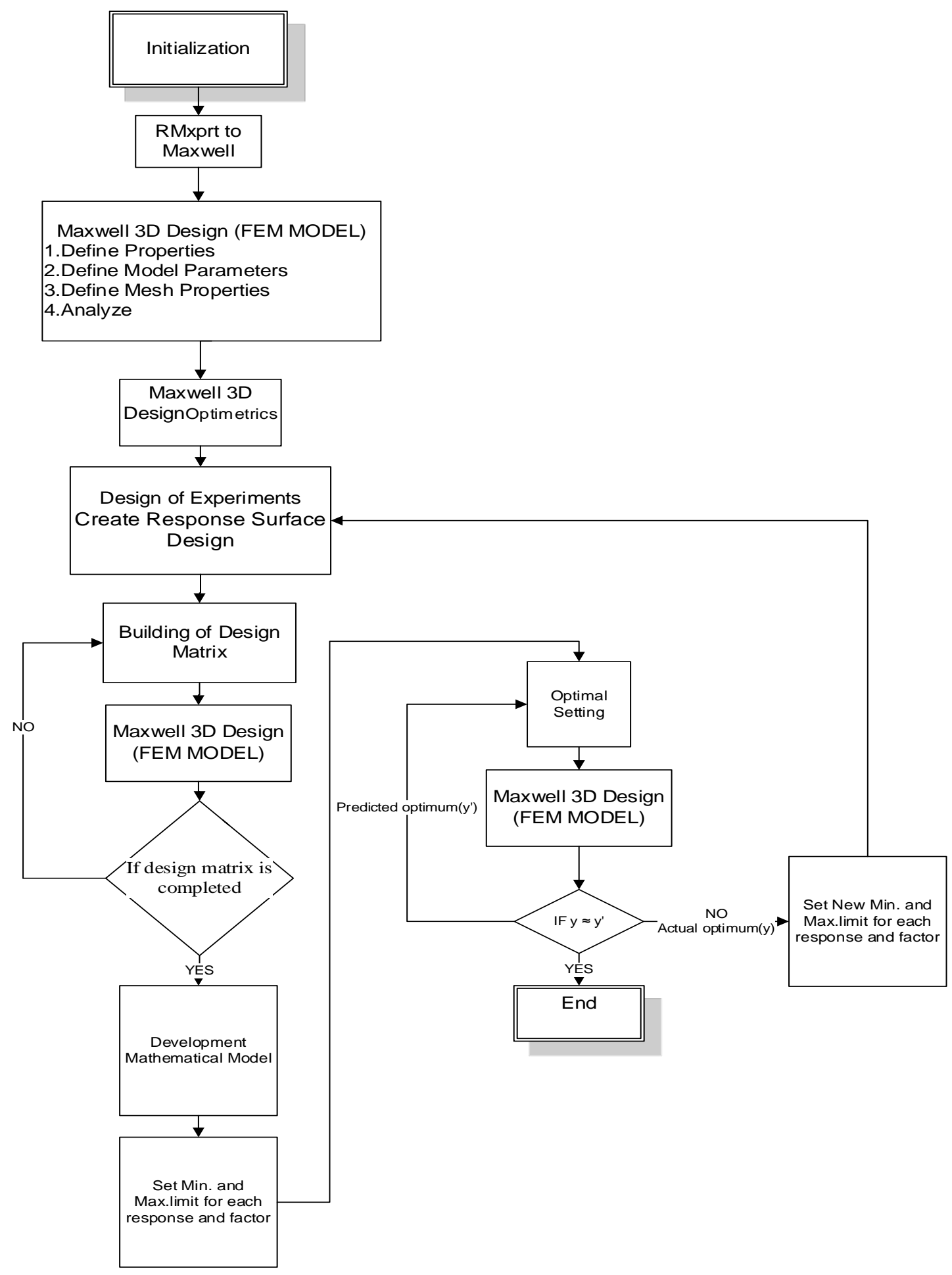

Figure 2. Ansys Maxwell response surface flow diagram

The automatic refinement adds design points to the DOE, until the response surface accuracy meets the requirements. Next goal is the creation of a response surface by interpolating through the calculated points by best curve fitting. Each design would have new response surface for each output parameter. In our study, three variables are set to be electrical loading, magnet thickness and magnet span to pole pitch ratio, as shown in Table 2. 
Table 2. Design variables and ranges

\begin{tabular}{ll}
\hline Variables & Range \\
\hline $\mathrm{A}$ & {$[18000-19500] \mathrm{A} / \mathrm{m}$} \\
$\mathrm{Lm}$ & {$[0.0045-0.006] \mathrm{m}$} \\
$\alpha_{p}$ & {$[0.65-0.8]$} \\
\hline
\end{tabular}

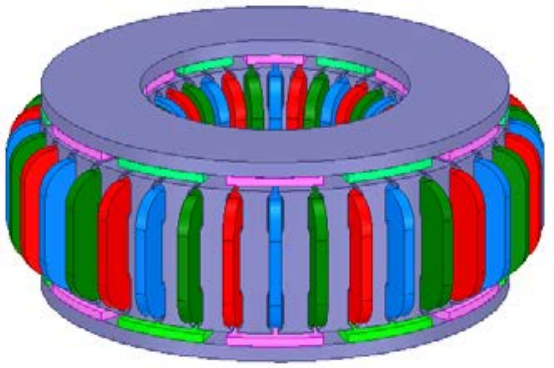

(a)

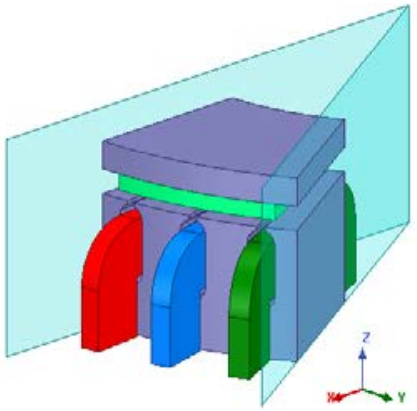

(b)

Figure 3. (a) A torus type designed machine and (b) master-slave surface configured fractional appearance

The purpose of the optimal design is to design a machine with high efficiency and low cost with a torque requirement of $25.8 \mathrm{Nm}$ to guarantee the $1288 \mathrm{VA}$ output power. Then these objectives are considered to minimize cogging torque and improvement general performance and efficiency as in Table 3 .

Table 3. Design objectives

\begin{tabular}{lc}
\hline Design Objective 1 & Weight \\
\hline Pout/Mass $\geq 130$ & {$[1]$} \\
Efficiency $\geq 0.92$ & {$[1]$} \\
$T_{\operatorname{cog}_{p p}}(0.01 \mathrm{~ms}-0.02 \mathrm{~ms})=0$ & {$[1]$} \\
\hline
\end{tabular}

\section{RESULTS and DISCUSSION}

After applying the optimization scheme shown in Fig. 2, the optimized results have been clarified as in Table 4. Note that in the simulations, the output power is considered to be fixed. However, the FEA cannot give the desired output power for the initial design in Maxwell environment.

Table 4. Optimization results

\begin{tabular}{lrrl}
\hline Input Variables & Initial Design & Optimized Design & Unit \\
\hline Electrical Loading $(A)$ & 19500 & 18710 & $\mathrm{~A} / \mathrm{m}$ \\
Pole pitch ratio $\left(\alpha_{p}\right)$ & 0.8 & 0.7802 & \\
Magnet Thickness $(\mathrm{Lm})$ & 0.0045 & 0.005254 & $\mathrm{~m}$ \\
Power Density $\left(P_{d}\right)$ & 0.214 & 0.263 & $\mathrm{~W} / \mathrm{cm}^{3}$ \\
Mass & 11.8 & 12.37 & $\mathrm{~kg}$ \\
Output Power $\left(P_{\text {out }}\right)$ & 1288 & 1641 & $\mathrm{VA}$ \\
Efficiency $(\eta)$ & 0.93 & 0.93 & \\
\hline
\end{tabular}




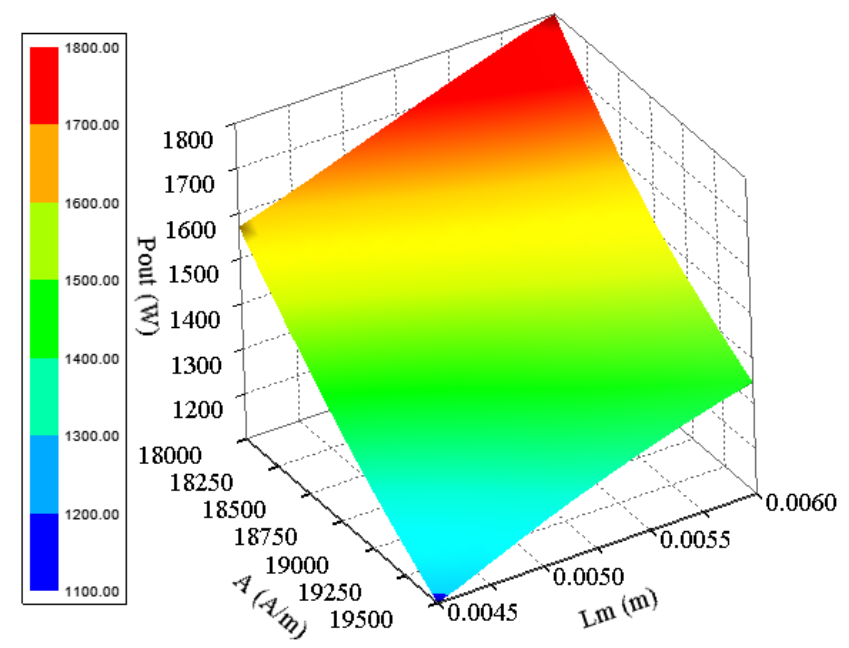

Figure 4. The output power deviations for the planes of the magnet thickness - electrical load

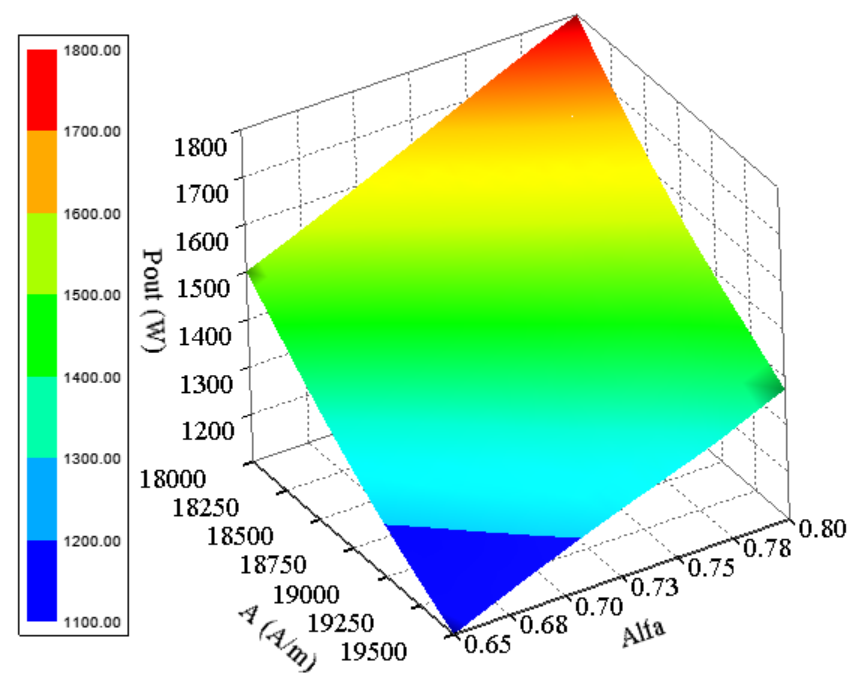

Figure 5. The output power deviations for the planes of the pole pitch ratio - electrical load

According to Table 4-5, the output power differences prove that the optimized machine is more powerful compared to the initial machine. Thus, the relevance of our analysis is notorious, and although the efficiency remains constant, a substantial increase occurs in power. According to literature, the power density of $263 \mathrm{~kW} / \mathrm{m}^{3}$ is a good value for the axial generators, when the power densities have changed between $6 \mathrm{~kW} / \mathrm{m}^{3}$ and $700 \mathrm{~kW} / \mathrm{m}^{3}$ [2]. In addition, some parametric relations are presented in Fig. 4-5 in order to understand the variable effects. By using the design objectives in Table 3, the performance deviations for the input variables are shown in Fig. 4-5 and Fig. 6.

Fig. 4 proves that the power increases almost linearly with the magnet thickness for lower electric loads, whereas the increasing trend gets lowered at higher electric loads. For the studied range, decreasing load yields to higher power. However, we expect a decrease beyond a certain electric load, which is lower than the impedance of the machine, as occurs usually with electrical devices [41].

The power relation in Fig. 5 is also similar to the first case, however a more linear - dependence exists for pole pitch ratio $\left(\alpha_{p}\right)$. Note that 0.8 gives the maximal power at the studied range. 
The mass-dependence on magnet thickness and the pole pitch ratio have similar attitudes according to Fig. 6. If each of them increase, the mass of the machine increases, too. The machine mass increases linearly with the magnet thickness and pole pitch ratio.
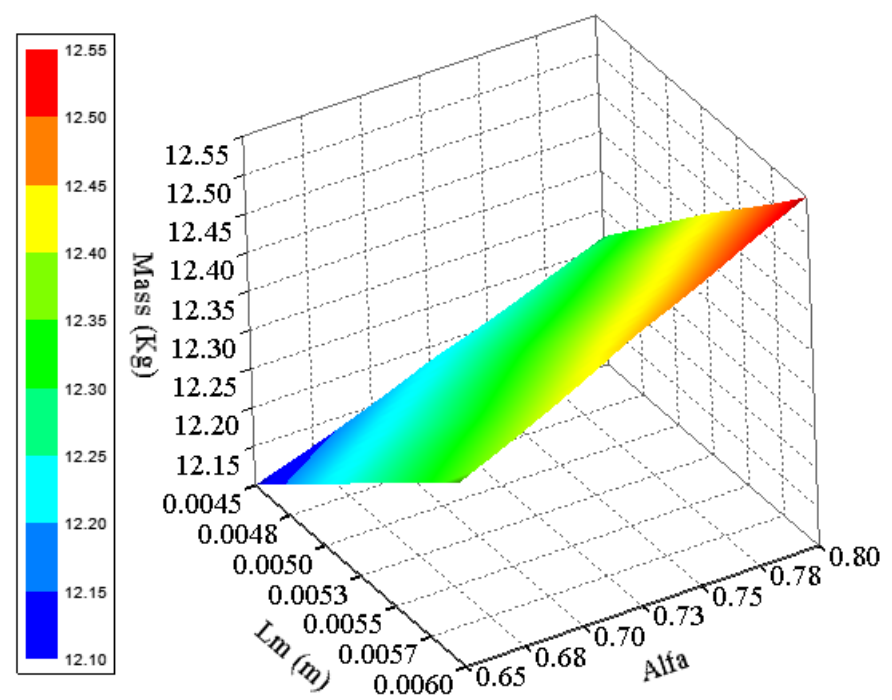

Figure .6 The machine weight deviations for the planes of the magnet thickness - pole pitch ratio

In terms of cogging torque, Fig. 7 has been depicted. Note that the cogging torque is created by the change in reluctance between the magnets and stator teethes. At lower speeds, torque ripples may result in undesirable speed variations, vibrations, and acoustic noise, which may affect the machine performance significantly. Thereby, the cogging torque should be minimized without lowering the machine performance. In the literature, there exist many methods to decrease the cogging torque of the AFMs. Magnet/slot shape change, pole/slot combination, screwing, angular or radial change of magnets/cores can be mentioned in that manner [2, 42, 43]. To measure the cogging torque by an experiment is particularly complex, therefore numerical analysis is used to calculate under parametrization. Consecutively, current has been applied through the windings in order to find the cogging torque effects. In the transient mode, Ansys Maxwell can calculate the torque values for each desired electrical angles. Depending on the rotor speed, the simulation time span is decreased in order to have sensitive results for smaller electrical angles. Depending on the rotor speed, the simulation time span is decreased in order to have sensitive result for smaller electrical angles. It is obvious from Fig. 7 that only a 3 degree skewing yields to lower torque values compared to the initial state.

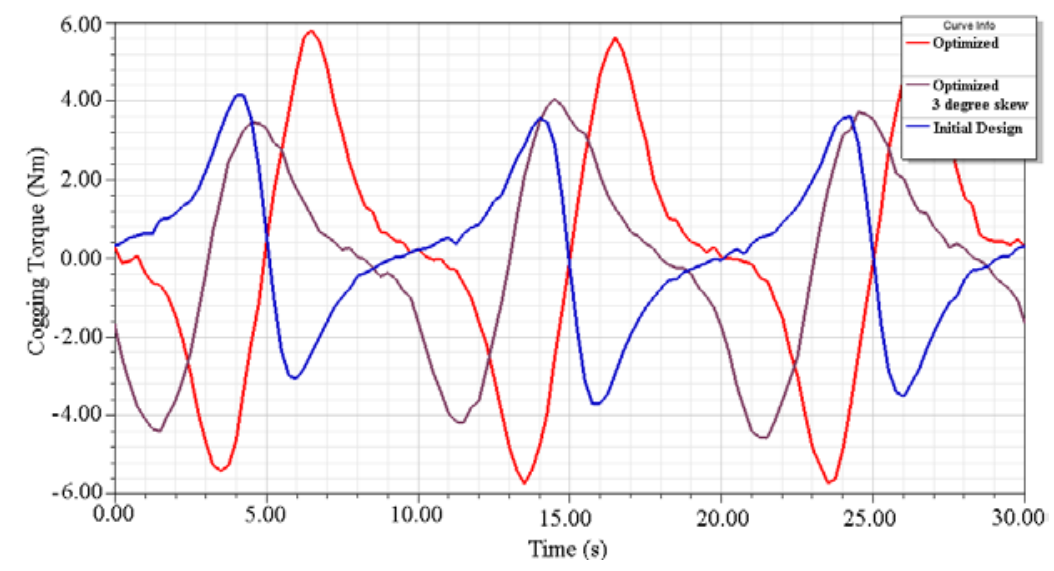

Figure 7. Variation of cogging torque 
Whereas, the optimized torque values can be larger than the lower one since the machine output power is also considered. It has been also observed that magnet thickness was not so effective to lower the cogging torque. Strictly speaking, $5 \%$ lower torque could be obtained compared to the rated torque value.

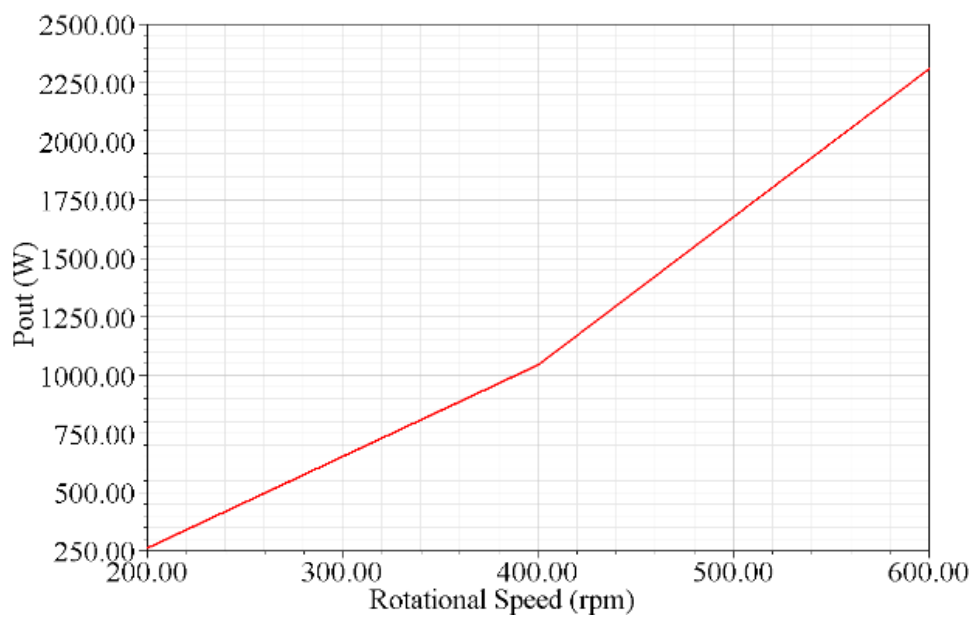

(a)

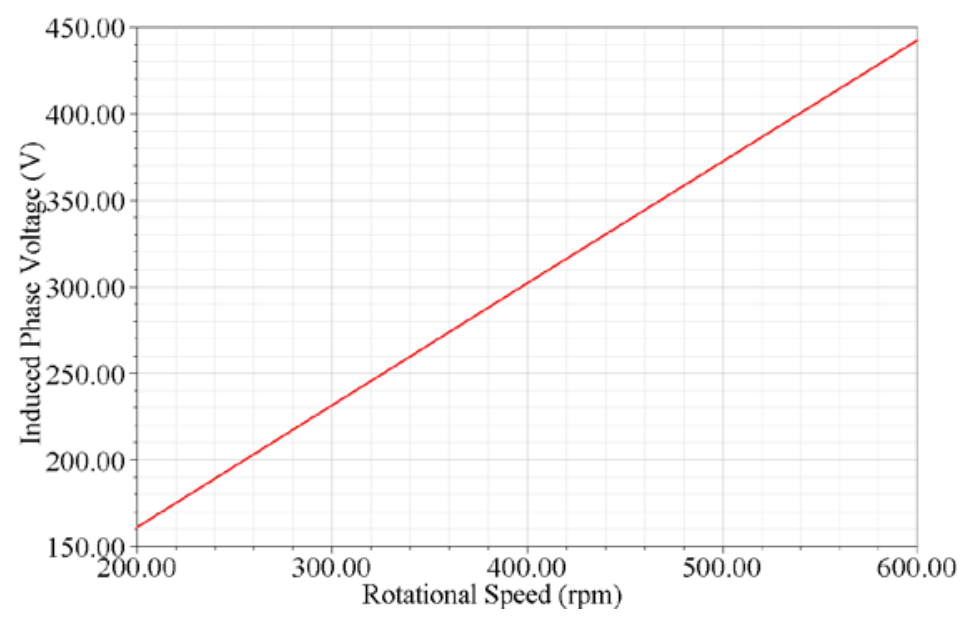

(b)

Figure 8. (a) The output power and (b) induced phase voltage versus rotor speed

The output power and induced phase voltage versus rotor speed are shown in Fig. 8. In the operated regime between $200 \mathrm{rpm}$ and $600 \mathrm{rpm}$, the increase in speed causes better power values. However, we expect that a rated speed must exist in order to get maximal power rate for higher speed values. In future works, it is considered that higher speeds should also be analyzed in that context. 


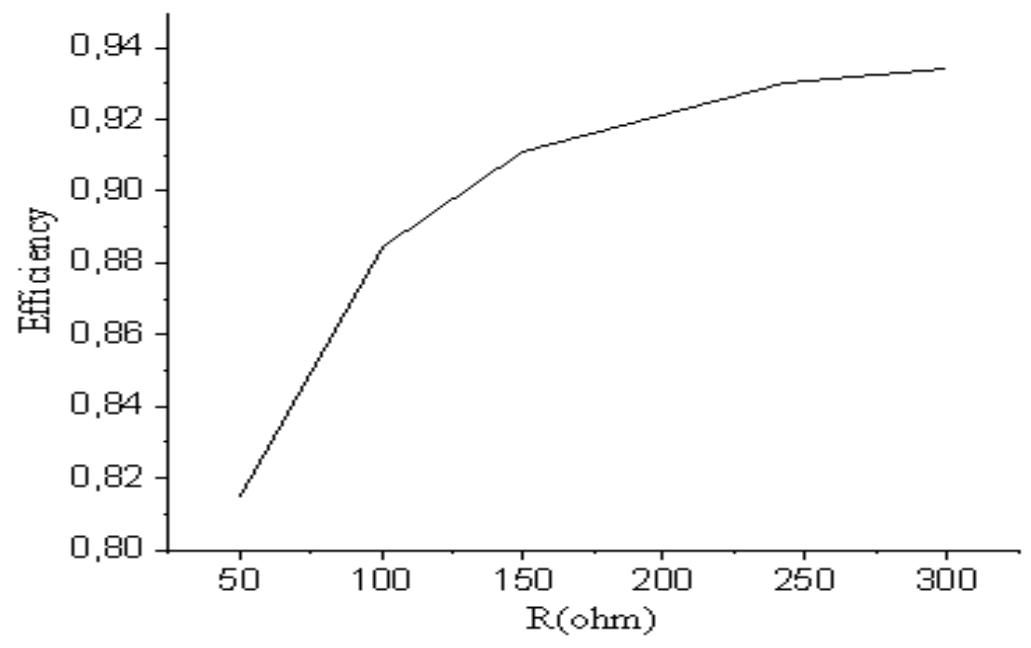

Figure 9. The efficiency of machine versus electrical load

As a concluding figure, the efficiency versus resistive load has depicted in Fig. 9. The increase in electrical load yield to an increase in efficiency. The tendency in increment decreases by the load and becomes fixed around $300 \mathrm{Ohm}$.

\section{CONCLUSIONS}

An optimization study has been performed for a torus type AFM motor with PM. The optimization has been realized with an initial design and assisted by the response surface optimization-based sizing equation after applying the input variables. In the procedure, the response surface results assisted us to obtain the maximum power per mass and efficiency for the preliminary design of a $1.5 \mathrm{~kW}$ twelve-pole motor. During the optimization, a continuous feed-back to the Ansys/Maxwell code from the three dimensional finite element analysis has been obtained and the best variable values have been obtained after re-cycling between two simulation environments. Compared to the initial design, a mass increase of $4.8 \%$ and a power increase of $27.4 \%$ have been provided as results of that optimization analysis, maintaining always constant the efficiency of the motor.

\section{REFERENCES}

[1] Kurt, E, Arslan, S, Demirtas, M. Cogging torque exploration of radially and angularly directed fluxes in a new PM generator with the multiple stators. In: Proceedings of the 7th. Int. Conf. \& Exh. Ecological Vehicles and Renewable Energies-EVER, 22-25 March 2012.

[2] Kurt, E., Gör, H., Döner, U. Electromagnetic design of a new axial and radial flux generator with the rotor back-irons. Int. J. Hydrogen Energy, 2016, 41(17), 7019-7026.

[3] Chalmers B.J., Spooner E. An axial-flux permanent-magnet generator for a gearless wind energy system. IEEE Trans. Energy Conversion, 1999, 14(2) 251-257.

[4] Profumo, F., Zhang, Z., Tenconi, A. Axial flux machines drives: A new viable solution for electric cars. IEEE Trans. Industrial Electronics, 1997, 44(1) 39-45.

[5] Brown, N., Haydock, L., Bumby, J.R. Foresight Vehicle: A Toroidal, axial flux generator for hybrid IC engine/battery electric vehicle applications. SAE Technical Paper, 2002.

[6] Jin, J., Charpentier, J.-F., Tang, T. Preliminary design of a TORUS type axial flux generator for directdriven tidal current turbine. In: Green Energy, 2014 International Conference on. IEEE, 2014. pp. 20-25. 
[7] Wiltuschnig, I.P., et al. A Study of the Influence of Quasi-Halbach Arrays on a Torus Machine. IEEE Trans. Magnetics, 2016, 52(7), 1-4.

[8] Kahourzade, S., et al. Design optimization and analysis of AFPM synchronous machine incorporating power density, thermal analysis, and back-EMF THD. Progress In Electromagnetics Research, 2013, 136, 327-367.

[9] Virtič, P., Vražić, M., Papa, G. Design of an axial flux permanent magnet synchronous machine using analytical method and evolutionary optimization. IEEE Trans. Energy Conversion, 2016, 31(1), 150-158.

[10] Jolly, L., Jabbar, M.A., Qinghua, L. Design optimization of permanent magnet motors using response surface methodology and genetic algorithms. IEEE Trans. Magnetics, 2005, 41(10), 3928-3930.

[11] Lim, D.-K., et al. Cogging torque minimization of a dual-type axial-flux permanent magnet motor using a novel optimization algorithm. IEEE Trans. Magnetics, 2013, 49(9), 5106-5111.

[12] Azzouzi, J., et al. Design optimization of an axial flux PM synchronous machine: comparison between DIRECT method and GAs method. In: Power Electronics and Motion Control Conference, 2006. EPEPEMC 2006. 12th International. IEEE, 2006. pp. 1094-1098.

[13] Qinghua, L.I.U., Jabbar, M.A., Khambadkone, A.M. Response surface methodology based design optimisation of interior permanent magnet synchronous motors for wide-speed operation. In: Power Electronics, Machines and Drives, 2004. (PEMD 2004). Second International Conference on (Conf. Publ. No. 498). IET, 2004. pp. 546-551.

[14] Ghasemi, A. Cogging torque reduction and optimization in surface-mounted permanent magnet motor using magnet segmentation method. Electric Power Components and Systems, 2014, 42(12), 1239-1248.

[15] Yu, J.-S., et al. Optimum design of stator and rotor shape for cogging torque reduction in interior permanent magnet synchronous motors. Journal of Power Electronics, 2013, 13(4), 546-551.

[16] Bremner, R.D. Rapid optimization of interior permanent magnet (IPM) machines using the response surface method and dimensionless parameters. Iowa State University, 2010.

[17] Jabbar. M.A., Jolly. L., Qinghua. L. Design optimisation of permanent magnet motors using response surface analysis. In: Digests 3rd International Conference on Electrical \& Computer Engineering. 2004. pp. 28-30.

[18] Abbaszadeh, K., Rezaee Alam, F., Teshnehlab, M. Slot opening optimization of surface mounted permanent magnet motor for cogging torque reduction. Energy Conversion and Management, 2012, 55, 108-115.

[19] Giurgea, S., et al. Multimodel optimization based on the response surface of the reduced FEM simulation model with application to a PMSM. IEEE Trans. Magnetics, 2008, 44(9), 2153-2157.

[20] Abbaszadeh, K., Rezaee Alam, F., Saied, S.A. Cogging torque optimization in surface-mounted permanentmagnet motors by using design of experiment. Energy Conversion and Management, 2011, 52(10), 30753082.

[21] Gao, X. K., et al. Robust design for torque optimization using response surface methodology. IEEE Trans. Magnetics, 2002, 38(2), 1141-1144.

[22] Saha S., Choi, G.-D., Cho, Y.-H. Optimal rotor shape design of LSPM with efficiency and power factor improvement using response surface methodology. IEEE Trans. Magnetics, 2015, 51(11), 1-4.

[23] Jiani, L., et al. Design Optimization and Analysis of a Dual-Permanent-Magnet-Excited Machine Using Response Surface Methodology. Energies, 2015, 8(9), 10127-10140.

[24] Hasanien, H.M., Abd-Rabou, A.S., Sakr, S.M. Design optimization of transverse flux linear motor for weight reduction and performance improvement using response surface methodology and genetic algorithms. IEEE Trans. Energy Conversion, 2010, 25(3), 598-605.

[25] Pourmoosa, A.A., Mirsalim, Mojtaba. Design Optimization, Prototyping, and Performance Evaluation of a Low-Speed Linear Induction Motor with Toroidal Winding. IEEE Trans. Energy Conversion, 2015, 30(4), 1546-1555.

[26] Arslan, S., Gürdal, O., Akkaya, O.S., The Design, Dimensioning and Optimization of a 1 Kva Tubular Linear Alternator, Inter. J. Development Research, 2016, 6(12), 10550-10559.

[27] Wang, G., et al. Decomposition-based multi-objective differential evolution particle swarm optimization for the design of a tubular permanent magnet linear synchronous motor. Engineering Optimization, 2013, 45(9), 1107-1127.

[28] Kim, S.-I., et al. Optimal design of slotless-type PMLSM considering multiple responses by response surface methodology. IEEE Trans. Magnetics, 2006, 42(4), 1219-1222. 
[29] Lee, J.H., et al. Optimum shape design of single-sided linear induction motors using response surface methodology and finite element method. In: Electrical Machines and Systems (ICEMS), 2011 International Conference on. IEEE, 2011. pp. 1-5.

[30] Park, J.M., et al. Rotor design on torque ripple reduction for a synchronous reluctance motor with concentrated winding using response surface methodology. IEEE Transactions on Magnetics, 2006, 42(10), 3479-3481.

[31]Choi, Y.C., Kim, H.-S., Lee, J.-H. Optimum design criteria for maximum torque density and minimum torque ripple of SynRM according to the rated wattage using response surface methodology. IEEE Trans. Magnetics, 2008, 44(11), 4135-4138.

[32] Ahn, H.-M., et al. Optimal Design of Permanent Magnetic Actuator for Permanent Magnet Reduction and Dynamic Characteristic Improvement using Response Surface Methodology. Journal of Electrical Engineering \& Technology, 2015, 10(3), 935-943.

[33] Cove, S.R., et al. Applying response surface methodology to small planar transformer winding design. IEEE Transactions on Industrial Electronics, 2013, 60(2), 483-493.

[34] Yang X., Patterson Dean, Hudgıns Jerry. Multi-objective design optimization of a single-sided axial Flux permanent magnet machine. In: Electrical Machines and Systems (ICEMS), 2013 International Conference on. IEEE, 2013. pp. 822-825.

[35] Hwang, C.-C., et al. Optimization for reduction of torque ripple in an axial flux permanent magnet machine. IEEE Transactions on Magnetics, 2009, 45(3), 1760-1763.

[36] Mahmoudi, A., et al. Design, analysis, and prototyping of an axial-flux permanent magnet motor based on genetic algorithm and finite-element analysis. IEEE Transactions on Magnetics, 2013, 49(4), 1479-1492.

[37]Huang, S., Aydın Metin, Lipo Thomas A. TORUS concept machines: pre-prototyping design assessment for two major topologies. In: Industry Applications Conference, 2001. Thirty-Sixth IAS Annual Meeting. Conference Record of the 2001 IEEE. IEEE, 2001. pp. 1619-1625.

[38]Huang, S., et al. A general approach to sizing and power density equations for comparison of electrical machines. IEEE Transactions on Industry Applications, 1998, 34(1), 92-97.

[39] Alpar, R. Uygulamalı İstatistik ve Geçerlilik-Güvenirlik, Ankara: Detay Publ., 2014, 1-668.

[40] Gao, X.K., et al. Robust design for torque optimization using response surface methodology. IEEE Trans. Magnetics, 2002, 38(2), 1141-1144.

[41] Uzun, Y., Kurt, E., Kurt, H.H. Explorations of displacement and velocity nonlinearities and their effects to power of a magnetically-excited piezoelectric pendulum. Sensors and Actuators A: Physical, 2015, 224, 119-130.

[42] Aydın, M. Magnet skew in cogging torque minimization of axial gap permanent magnet motors. In: Electrical Machines, 2008. ICEM 2008. 18th International Conference on. IEEE, 2008. pp. 1-6.

[43] Kurt, E., et al. Electromagnetic analyses of two axial-flux permanent magnet generators (PMGs). In: Power Engineering, Energy and Electrical Drives (POWERENG), 2013 Fourth International Conference on. IEEE, 2013. pp. 290-294. 